\title{
Clinical features and prognostic factors of early-onset sepsis: a 7.5-year experience in one neonatal intensive care unit
}

\author{
Se Jin Kim, MD, Ga Eun Kim, MD, Jae Hyun Park, MD, PhD, Sang Lak Lee, MD, PhD, Chun Soo Kim, MD, PhD \\ Department of Pediatrics, Keimyung University School of Medicine, Daegu, Korea
}

Purpose: In this study, we investigated the clinical features and prognostic factors of early-onset sepsis (EOS) in neonatal intensive care unit (NICU) patients.

Methods: A retrospective analysis was conducted on medical records from January 2010 to June 2017 (7.5 years) of a university hospital NICU.

Results: There were 45 cases of EOS (1.2\%) in 3,862 infants. The most common pathogen responsible for EOS was group B Streptococcus (GBS), implicated in 10 cases (22.2\%), followed by Escherichia coli, implicated in 9 cases (20\%). The frequency of gram-positive sepsis was higher in term than in preterm infants, whereas the rate of gram-negative infection was higher in preterm than in term infants $(P<0.05)$. The overall mortality was $37.8 \%$ ( 17 of 45 ), and $47 \%$ of deaths occurred within the first 3 days of infection. There were significant differences in terms of gestational age (26.8 weeks vs. 35.1 weeks) and birth weight (957 g vs. 2,520 g) between the death and survival groups. After adjustments based on the difference in gestational age and birth weight between the 2 groups, gram-negative pathogens (odds ratio [OR], 42; $95 \%$ confidence interval [Cl], 1.4-1,281.8) and some clinical findings, such as neutropenia (OR, 46; 95\% $\mathrm{Cl}, 1.3-1,628.7)$ and decreased activity (OR, 34; $95 \% \mathrm{Cl}, 1.8-633.4)$, were found to be associated with fatality.

Conclusion: The common pathogens found to be responsible for EOS in NICU patients are GBS and E. coli. Gram-negative bacterial infections, decreased activity in the early phase of infection, and neutropenia were associated with poor outcomes.

Key words: Early-onset sepsis, Clinical features, Prognosis, Neonatal intensive care unit

\section{Introduction}

Although the survival rate of newborn infants has been improved by advance in neonatal intensive therapy, the incidence of infections in high-risk infants is not decreasing. The overall incidence of early-onset sepsis (EOS), defined as sepsis occurring within 72 hours of birth, is 1-4.6 per 1,000 live births worldwide, ${ }^{1,2)}$ but increases to $11-36$ per 1,000 live births in very low birth weight infants (VLBWIs). ${ }^{1,3,4)}$ VLBWIs with EOS have a higher rate of mortality and complications, including bronchopulmonary dysplasia, severe ventricular hemorrhage, sever retinopathy of prematurity and neurodevelopmental defects, than those without infection. ${ }^{3-5)}$

EOS is usually caused by microorganisms, including bacteria, that are present in the birth canal of the mother, and the infection occurs before or during labor. Various obstetric factors, including chorioamnionitis, premature rupture of membranes (PROM), maternal fever, and preterm labor, are associated with EOS. ${ }^{6-8}$ The incidence of EOS and the distribution of causative organisms vary by geographic region and race, ${ }^{9,10)}$ and also depends on the medical

Corresponding author: Chun Soo Kim, MD, PhD Department of Pediatrics, Keimyung University School of Medicine, 56 Dalseong-ro, Jung-gu, Daegu 41931, Korea

Tel: $+82-53-250-7526$

Fax: +82-53-250-7783

E-mail: cskim@dsmc.or.kr https://orcid.org/0000-0003-3888-334X

Received: 26 July, 2018

Revised: 17 September, 2018

Accepted: 27 September, 2018
Copyright (C) 2018 by The Korean Pediatric Society

This is an open-access article distributed under the terms of the Creative Commons Attribution NonCommercial License (http://creativecommons.org/ licenses/by-nc/4.0/) which permits unrestricted noncommercial use, distribution, and reproduction in any medium, provided the original work is properly cited. 
environment at individual hospitals, such as the application of maternal chemoprophylaxis and the proportion of VLBWI among neonatal intensive care unit (NICU) patients. ${ }^{9,11)}$ Intrapartum antibiotic prophylaxis (IAP) using ampicillin has been administered to pregnant women with group B Streptococcus (GBS) rectovaginal colonization and other obstetric risk factors for EOS in the United States (US) since 1996, and the incidence of EOS due to GBS has decreased. ${ }^{12)}$ However, infection by $E$. coli has not been reduced, ${ }^{13)}$ and infection by resistant strains has been increasing. ${ }^{14)}$ Therefore, serial investigations of the causative organisms of EOS in individual NICUs are important for infection control.

Infants suffering from EOS show a high mortality rate of approximately $11 \%-37 \%, 1,13)$ despite advance in intensive care, including early antibiotic therapy. The time of death due to sepsis is usually within 2 weeks after the onset of the infection. ${ }^{1,5)}$ The incidence of fatality is affected by the gestational age and birth weight of babies with infections. ${ }^{1)}$ Additionally, the outcomes of sepsis may differ depending on the causative pathogens and clinical findings for the infected patients. ${ }^{13,15,16)}$ However, clinical studies on the prognostic factors associated with the mortality of EOS are still lacking. This study was undertaken to investigate the clinical features and prognostic factors related to fatality of EOS in NICU patients.

\section{Materials and methods}

This study was conducted on patients with EOS at the NICU of a university hospital in Korea over a 7.5-year period (Jan 2010Jun 2017). The medical records and radiographic findings of the subjects were retrospectively reviewed. This study was approved by the Institutional Review Board of Keimyung University Dongsan Hospital (approval number: 2018-06-027). Informed consent was waived by the board.

\section{Study design}

The subjects were those who had clinical signs of infection and/ or elevated C-reactive protein (CRP) among the patients who were identified with causative organisms in blood cultures within 72 hours of life. ${ }^{1,3)}$ In patients with skin flora, including coagulasenegative staphylococci, the diagnosis of sepsis was based on both the presence of clinical signs of infection and elevated CRP, or the same bacteria were continuously detected in the blood culture performed within 48 hours. Among patients who were positive for microorganisms in their blood specimens within 3 days of life, those with contaminants were excluded from the study. The following were assessed as contamination: if contaminants (Corynebacterium, Diphtheroids, Micrococci, and Propionibacterium) or more than one organism were detected in the blood culture and antibiotics were discontinued within 5 days in the surviving patient. ${ }^{1,5)}$ Using the medical data of patients with EOS, the incidence of sepsis and clinical findings of infections, including causative organisms, symptoms and signs, laboratory findings, mortality, and risk factors associated with fatality, were investigated.

\section{Definitions of variables}

Clinical symptoms associated with sepsis were limited to the following: decreased activity, fever, tachycardia, bradycardia, apnea, abdominal distension, and hypotension. Clinical symptoms and laboratory tests in the early phase of infection were limited to findings within the first 48 hours from the time of blood culture. Chorioamnionitis included both a clinical and histological diagnosis. ${ }^{8)}$ Maternal hypertension included all four types of hypertension in pregnancy classified as gestational hypertension, preeclampsia, eclampsia, and chronic hypertension of any etiology. ${ }^{17)}$ The use of antenatal steroids was limited to 2 or more doses of dexamethasone. The use of antenatal antibiotics was limited to the administration of drugs for more than 3 days. Apnea was defined as temporary cessation of breathing for a duration of $>20$ seconds or when accompanied by bradycardia and desaturation, even though the duration was $<20$ seconds. ${ }^{18)}$ Hypotension was defined as a mean blood pressure of $<30$ mmHg. ${ }^{19)}$ Neutropenia was defined as a neutrophil count of $<1,000 /$ $\mu \mathrm{L}^{20)}$ Respiratory distress syndrome (RDS) was limited to the cases undergoing surfactant replacement treatments. Pneumothorax was limited to cases with chest tube insertion. Pulmonary hemorrhage was limited to cases that required interventional therapies, including tracheal instillation of epinephrine. Patent ductus arteriosus (PDA) was limited to cases with hemodynamic significance confirmed by echocardiography and associated symptoms. Acute kidney injury was defined as both oliguria $(<1 \mathrm{~mL} / \mathrm{kg} / \mathrm{hr})$ and elevated serum creatinine $(>1.5 \mathrm{mg} / \mathrm{dL}){ }^{21)}$ Empirical antimicrobial therapy for EOS was based on the use of ampicillin and gentamicin. Also, the results of culture test for maternal specimens were considered. The empirical antimicrobial regimen was considered appropriate if at least one antibiotic is susceptible to the causative organism; otherwise, it was assessed to be inappropriate. Fulminant infection was defined as deaths within 48 hours after the onset of sepsis. ${ }^{22)}$ Fatality in patients with sepsis was limited to death within 14 days after infection.

\section{Statistical analysis}

Data were analyzed using IBM SPSS Statistics ver. 20.0 (IBM Co., Armonk, NY, USA). The chi-square test and Fisher exact test were used for categorical variables, and the Man-Whitney $U$ test and $t$ test were used for continuous variables. Multiple logistic regression analysis was performed to detect the risk factors associated with the prognosis of EOS. $P$ values less than 0.05 were considered statistically significant. 


\section{Results}

\section{Study population}

Of the total 3,862 patients, microorganisms were identified in the blood samples of 167 babies (4.3\%). Among the infants with identified microbes in their blood specimens, 45 were diagnosed as infected, and the remaining 122 were classified as cases with contaminants. Among the babies with contaminants, mixed bacteria were detected in 2 cases, and 2 different contaminants were detected in blood culture tests at intervals of 48 hours in another. The EOS group was classified into 17 deaths and 28 survivors (Fig. 1).



Fig. 1. Schematic diagram showing a 2-step classification for the study population. First, infants with microbes identified in their blood specimens were classified as infected or contaminated. Second, infants with true infections were divided into the death and survival groups.

Table 1. Distribution of pathogens isolated from patients with earlyonset sepsis $(n=45)$

\begin{tabular}{lccc}
\hline Microorganisms & Term $(\mathrm{n}=14)$ & Preterm $(\mathrm{n}=31)$ & Total, $\mathrm{n}(\%)$ \\
\hline Gram-positive bacteria & 12 & 16 & $28(62.2)$ \\
Streptococcus group B & 5 & 5 & $10(22.2)$ \\
Staphylococcus aureus & 4 & 1 & $5(11.1)$ \\
Staphylococcus epidermidis & 1 & 2 & $3(6.7)$ \\
Streptococcus mitis & 1 & 2 & $3(6.7)$ \\
Enterococcus faecalis & 1 & 1 & $2(4.4)$ \\
Enterococcus faecium & 0 & 2 & $2(4.4)$ \\
Staphylococcus capitis & 0 & 1 & $1(2.2)$ \\
Streptococcus anginosus & 0 & 1 & $1(2.2)$ \\
Streptococcus sanguinis & 0 & 1 & $1(2.2)$ \\
Gram-negative bacteria & 2 & 14 & $16(35.6)$ \\
Escherichia coli & 1 & 8 & $9(20.0)$ \\
Pseudomonas aeruginosa & 0 & 3 & $3(6.7)$ \\
Enterobacter aerogenes & 0 & 1 & $1(2.2)$ \\
Enterobacter cloacae & 0 & 1 & $1(2.2)$ \\
Haemophilus influenzae & 0 & 1 & $1(2.2)$ \\
Proteus mirabilis & 1 & 0 & $1(2.2)$ \\
Fungus & 0 & 1 & $1(2.2)$ \\
Candida albicans & 0 & 1 & $1(2.2)$ \\
\hline
\end{tabular}

\section{Distribution of microorganisms}

In a total of 45 subjects, the most common pathogen responsible for EOS was GBS in 10 cases (22.2\%), followed by E. coli in 9 cases $(20 \%)$. The rate of gram-positive sepsis was higher in term than in preterm infants (85.7\% vs. 51.6\%) $(P<0.05)$. In contrast, the rate of gram-negative infection was higher in preterm than in term infants (45.2\% vs. $14.3 \%)(P<0.05)$ (Table 1$)$.

\section{Mortality and time of death}

The overall mortality within 14 days after the infection was 37.8 $\%$ (17 of 45). The number of deaths was the highest at 8 (47.1\%) during the first 3 days after infection, 4 (23.5\%) after 4-7 days, and 5 (29.4\%) after 8-14 days (Table 2). Fulminant infections occurred in 7 cases (15.6\%), and all were preterm infants. In detail, 3 cases occurred in patients with Pseudomonas aeruginosa and E. coli sepsis, respectively; the remaining 1 developed in infants with Staphylococcus aureus sepsis.

\section{Incidence of fatal infections by causative organisms}

The rate of fatality in patients with $P$. aeruginosa, E. coli and GBS sepsis was 100\%, 77.8\%, and 10\%, respectively. The overall rate of fatal infections in infants with gram-negative sepsis was $68.8 \%$,

Table 2. Mortality and time of death of patients with early-onset sepsis $(\mathrm{n}=45)$

\begin{tabular}{lc}
\hline Variable & o. (\%) \\
\hline Death & $17(37.8)$ \\
Time to death after infection (day) & \\
$1-3$ & $8(47.1)$ \\
$4-7$ & $4(23.5)$ \\
$8-14$ & $5(29.4)$ \\
\hline
\end{tabular}

Table 3. Causative organisms for incidences of fatal infections $(n=45)$

\begin{tabular}{lc}
\hline Microorganism & No. (\%) \\
\hline Gram-positive bacteria $^{*}$ Streptococci other* & $21.4)$ \\
Coagulase-negative staphylococci $^{*} / 5(40.0)$ \\
Enterococci & $1 / 4(25.0)$ \\
Staphylococcus aureus & $1 / 4(25.0)$ \\
Streptococcus group B & $1 / 5(20.0)$ \\
Gram-negative bacteria & $1 / 10(10.0)$ \\
Pseudomonas aeruginosa & $11 / 16(68.8)$ \\
Haemophilus influenzae & $3 / 3(100)$ \\
Escherichia coli & $1 / 1(100)$ \\
Enterobacter species & $7 / 9(77.8)$ \\
Proteus mirabilis & $0 / 2(0)$ \\
Fungus & $0 / 1(0)$ \\
Candida albicans & $0 / 1(0)$ \\
\hline
\end{tabular}

*Defined as excluding Streptococcus group B 
which was higher than the $21.4 \%$ for patients with gram-positive infections $(P<0.005)$ (Table 3$)$.

\section{Perinatal and clinical findings}

There was a significant difference in terms of gestational age (26.8 \pm 3.3 weeks vs. $35.1 \pm 4.3$ weeks) and birth weight $(957.1 \pm 542.4$ $\mathrm{g}$ vs. $2,520.4 \pm 924.4 \mathrm{~g})$ between the death and survival groups $(P<$ 0.001). Furthermore, the proportion of VLBWI was higher in the death group than in the survival group (82.4\% vs. 14.3\%) $(P<0.001)$. The 1-min and 5-min Apgar scores were lower in the death group $(P<0.001)$. The frequency of chorioamnionitis, antenatal steroid and antibiotic therapy was also higher in the death group $(P<0.05)$. In a comparison of clinical symptoms during the early phase of infection, the frequencies of several variables, including decreased activity, bradycardia, hypotension, and fever, were different between the death and survival groups $(P<0.05)$. Among the laboratory findings, elevated CRP and leukopenia were the most common findings (64.4\% and 33.3\%, respectively); however, there were no differences between the 2 groups. The rate of neutropenia was significantly higher in the death group than in the survival group $(P<0.005)$. Moreover, in a comparison of comorbid diseases in the early phase of infection, several factors, including RDS, PDA, and pulmonary hemorrhage, were more common in the death group than in the survival group $(P<0.05)$. Meningitis was complicated in 2 term infants with GBS sepsis, both of whom survived. The appropriateness of empiric antimicrobial therapy was not different between the 2 groups (Table 4).

\section{Prognostic factors of fatal outcome}

Logistic regression analysis of individual variables was performed to adjust for differences in gestational age and birth weight between the death and survival groups. Gram-negative pathogens (odds ratio [OR], 42; 95\% confidence interval [CI], 1.4-1,281.8) and some clinical findings, such as neutropenia (OR, 46; 95\% CI, 1.3-1,628.7) and decreased activity (OR, 34; 95\% CI, 1.8-633.4), were associated with fatality of sepsis after adjusting for these differences (Table 5).

\section{Discussion}

According to recent data from the Korean Neonatal Network $(\mathrm{KNN}){ }^{4)}$ the incidence of EOS, defined as sepsis occurring within 3 days of life, was 3.6\%. In this study, according to data from a single hospital over a 7.5-year period, EOS developed in 1.2\% of all NICU patients. The KNN investigated VLBWI among NICU patients. The difference between the incidence reported by the KNN and this study can be explained by the differences in gestational age and birth weight of the infants in the 2 study populations. The incidence of EOS increases with lower gestational age and body weight. In a national study performed in the US, ${ }^{1)}$ the overall rate of EOS was
Table 4. Perinatal and clinical findings in patients with early-onset sepsis

\begin{tabular}{|c|c|c|c|}
\hline Variable & Death $(n=17)$ & Survival $(n=28)$ & $P$ value \\
\hline \multicolumn{4}{|l|}{ Perinatal characteristics } \\
\hline Gestational age (wk) & $26.8 \pm 3.3$ & $35.1 \pm 4.3$ & $<0.001$ \\
\hline Birth weight (g) & $957.1 \pm 542.4$ & $2,520.4 \pm 924.4$ & $<0.001$ \\
\hline Birth weight, $<1,500 \mathrm{~g}$ & $14(82.4)$ & $4(14.3)$ & $<0.001$ \\
\hline Cesarean delivery & $14(82.4)$ & $15(53.6)$ & 0.051 \\
\hline Sex, male:female & $11: 6$ & $15: 13$ & 0.463 \\
\hline Birth place, inborn:outborn & $17: 0$ & $22: 6$ & 0.069 \\
\hline 1-Min Apgar score & $5.3 \pm 1.5$ & $7.0 \pm 1.1$ & $<0.001$ \\
\hline 5-Min Apgar score & $7.1 \pm 1.1$ & $8.4 \pm 0.7$ & $<0.001$ \\
\hline Chorioamnionitis & 15 (88.2) & $8(28.6)$ & $<0.001$ \\
\hline Antenatal steroid & $10(58.8)$ & $3(10.7)$ & 0.001 \\
\hline Antenatal antibiotics & $7(41.2)$ & $2(7.1)$ & 0.017 \\
\hline Maternal hypertension & $2(11.8)$ & $2(7.1)$ & 0.626 \\
\hline Rupture of membranes, $\geq 18 \mathrm{hr}$ & $2(11.8)$ & $4(14.3)$ & 1.000 \\
\hline \multicolumn{4}{|l|}{ Clinical symptoms } \\
\hline Decreased activity & $13(76.5)$ & $5(17.9)$ & $<0.001$ \\
\hline Tachycardia, >160/min & $13(76.5)$ & $16(57.1)$ & 0.189 \\
\hline Bradycardia, $<100 /$ min & $8(47.1)$ & $4(14.3)$ & 0.034 \\
\hline Hypotension & $10(58.8)$ & $0(0)$ & $<0.001$ \\
\hline Apnea & $3(17.6)$ & $4(14.3)$ & 1.000 \\
\hline Abdominal distension & $2(11.8)$ & $3(10.7)$ & 1.000 \\
\hline Fever, $\geq 37.8^{\circ} \mathrm{C}$ & $1(5.9)$ & $10(35.7)$ & 0.033 \\
\hline \multicolumn{4}{|l|}{ Laboratory findings } \\
\hline WBC, $\geq 20,000 / \mathrm{mm}^{3}$ & $2(11.8)$ & $0(0)$ & 0.137 \\
\hline WBC, $<5,000 / \mathrm{mm}^{3}$ & $8(47.1)$ & $7(25)$ & 0.128 \\
\hline Neutrophil, $\geq 7,000 / \mathrm{mm}^{3}$ & $3(17.6)$ & 8 (28.6) & 0.493 \\
\hline Neutrophil, $<1,000 / \mathrm{mm}^{3}$ & $7(41.2)$ & $1(3.6)$ & 0.003 \\
\hline Lymphocyte, $\geq 4,000 / \mathrm{mm}^{3}$ & $1(5.9)$ & $0(0)$ & 0.378 \\
\hline Lymphocyte, $<1,000 / \mathrm{mm}^{3}$ & $4(23.5)$ & $9(32.1)$ & 0.737 \\
\hline Neutrophil-to-lymphocyte ratio & $1.9 \pm 3.2$ & $5.1 \pm 7.6$ & 0.106 \\
\hline Platelet, $<150,000 / \mathrm{mm}^{3}$ & $6(35.3)$ & $3(10.7)$ & 0.063 \\
\hline C-reactive protein, $\geq 0.5 \mathrm{mg} / \mathrm{dL}$ & $9(52.9)$ & 20 (71.4) & 0.209 \\
\hline \multicolumn{4}{|l|}{$\begin{array}{l}\text { Comorbid diseases and empirical } \\
\text { antibiotics }\end{array}$} \\
\hline Respiratory distress syndrome & $17(100)$ & $9(32.1)$ & $<0.001$ \\
\hline Patent ductus arteriosus & $6(35.3)$ & $0(0)$ & 0.002 \\
\hline Pulmonary hemorrhage & $4(23.5)$ & $0(0)$ & 0.016 \\
\hline $\begin{array}{l}\text { Intraventricular hemorrhage, } \\
\text { zstage III }\end{array}$ & $2(11.8)$ & $0(0)$ & 0.137 \\
\hline Acute kidney injury & $1(5.9)$ & $0(0)$ & 0.378 \\
\hline Necrotizing enterocolitis, zstage ॥ & $1(5.9)$ & $0(0)$ & 0.378 \\
\hline Pneumothorax & $1(5.9)$ & $0(0)$ & 0.378 \\
\hline Meningitis & $0(0)$ & $2(7.1)$ & 0.519 \\
\hline Inadequate antimicrobial regimen & $6(35.3)$ & $7(25)$ & 0.511 \\
\hline
\end{tabular}

Values are presented as mean \pm standard deviation or number (\%). 
Table 5. Logistic regression analysis adjusted for differences in gestational age and birth weight between the death and survival groups

\begin{tabular}{lccc}
\hline Varaible & $\beta$-coefficient & OR (95\% Cl) & $P$ value \\
\hline Decreased activity & 3.527 & $34.032(1.829-633.369)$ & 0.018 \\
Gram-negative pathogens & 3.745 & $42.289(1.395-1281.829)$ & 0.031 \\
Neutropenia & 3.830 & $46.057(1.302-1628.646)$ & 0.035 \\
Antenatal steroid & - & - & 0.178 \\
Bradycardia & - & - & 0.245 \\
Fever & - & - & 0.263 \\
5-Min Apgar score & - & - & 0.557 \\
Chorioamnionitis & - & - & 0.716 \\
1-Min Apgar score & - & - & 0.749 \\
Antenatal antibiotics & - & - & 0.840 \\
Hypotension & - & - & 0.998 \\
Respiratory distress syndrome & - & - & 0.998 \\
Patent ductus arteriosus & - & - & 0.999 \\
Pulmonary hemorrhage & - & - & 0.999 \\
\hline
\end{tabular}

0.98 cases per 1,000 live births. Specifically, rates of infection were $10.96,1.38$, and 0.57 per 1,000 live births in infants with a birth weight of 401-1,500 g, 1,501-2,500 g, and >2,500 g, respectively.

Generally, pathogens causing EOS are more common in grampositive bacteria than gram-negative bacteria, ${ }^{1,9,13)}$ and the most frequent pathogen is GBS. ${ }^{1,9)}$ However, according to data limited to VLBWI, gram-negative pathogens are more common than grampositive organisms, ${ }^{3)}$ and E. coli is the most common pathogen. ${ }^{1,3)}$ In developing countries where the level of health care is low and the delivery environment is poorly sanitized, other gram-negative bacteria, including Klebsiella pneumonia and Enterobacter cloacae, may be the most common pathogens. ${ }^{10)}$ The incidence of EOS by GBS infection has been decreasing since the introduction of IAP in the US, with 1.7 cases per 1,000 live births in the early 1990s and 0.34-0.37 cases per 1,000 live births in 2003-2008 period. ${ }^{12)}$ Nonetheless, GBS is still the most common organism in neonatal EOS, while $E$. coli is an increasing pathogen, especially in preterm infants. ${ }^{13)}$ In this study, similar to previous reports, the common pathogens responsible for EOS were GBS and E. coli. In detail, the number of cases with GBS sepsis was the same in both term and preterm infants (5 vs. 5); however, the number of cases with $E$. coli infection was higher in preterm than in full-term infants (8 vs. 1).

The mortality of neonatal EOS is inversely related to gestational age and birth weight. ${ }^{1)}$ In the current study of total NICU patients regardless of gestational age, the mortality rate for patients with EOS was 37.8\%, which can be considered as high. However, the fact that the mean gestational age was 27.8 weeks and the mean birth weight was $957.1 \mathrm{~g}$ in the death group should be considered, and direct comparison is difficult because the demographic characteristics of the subjects were different in each study. ${ }^{1,4)}$ Moreover, the mortality rate of infants with sepsis varies according to causative pathogens, ${ }^{9,15)}$ and gram-negative infection is associated with a higher mortality than gram-positive infection. ${ }^{13,15)}$ In this study, the mortality of patients with gram-negative sepsis was 68.8\%, which was higher than the $21.4 \%$ of patients with gram-positive sepsis. Specifically, the mortality of infants with E. coli sepsis was 77.8\%, while the mortality of infants with GBS sepsis was 10\%. Fulminant infections that result in fatal outcomes in the early phase of infections are often associated with gram-negative sepsis, including $P$. aeruginos $a$ and $E$. coli, especially in extremely preterm infants with septic shock. ${ }^{16,22)}$ In this study, 6 of the 7 fulminant infections were caused by gram-negative sepsis, and 5 of the affected patients were VLBWI. The shorter the time interval between the onset of infection and the time of death in patients with sepsis, the more likely it is that the infection was directly responsible for the death. ${ }^{23)}$ In this study, the proportions of deaths during the first 3 days and first 7 days after the onset of infection were $47.1 \%$ and $70.6 \%$, respectively, similar to previous reports. ${ }^{1,5)}$

The 3 major risk factors for EOS in newborn infants are chorioamnionitis, PROM $\geq 18$ hours, and inadequate IAP in the at-risk group. ${ }^{24)}$ In infants with EOS, the rate of chorioamnionitis is 33\%$77 \%,{ }^{1,4,5,8)}$ and this varies depending on the diagnostic method or the compliance with histologic examination. In this study, both clinical and histologic findings were included in the diagnosis, and the rate of chorioamnionitis was 51.1\%, however, histologic examinations were not performed in some patients. Although 33\%$44 \%$ of patients with EOS are reported to have prolonged PROM, ${ }^{1,4,5}$ only $13.3 \%$ of the subjects in this study were affected. The application of IAP in pregnant women with risk factors, including rectovaginal colonization of GBS, PROM, fever, or preterm labor, is effective in preventing GBS sepsis; ${ }^{12)}$ however, the guideline are yet to be established in Korea. IAP has recently been applied to some patients during this study period. Therefore, it is necessary to evaluate the effectiveness of chemoprophylaxis in the future. The rate of concomitant meningitis in infants with EOS is reported to be $4 \%-9 \%,{ }^{1,13,25,26)}$ and it developed in $4.4 \%$ of the subjects in this study. Concomitant meningitis can be a poor prognostic factor in infants with EOS; specifically, meningitis caused by gram-negative bacteria in VLBWI is associated with fatal outcomes. ${ }^{25}$ In this study, meningitis occurred in 2 term infants with GBS sepsis but was not associated with death.

In this study, logistic regression analysis was performed to adjust for the significant differences in gestational age (26.8 weeks vs. 35.1 weeks) and birth weight (957 g vs. 2,520 g) between the death and survival groups. Gram-negative pathogens (OR, 42; 95\% CI, $1.4-1,281.8)$ and some clinical findings, such as neutropenia (OR, 46 ; 95\% CI, 1.3-1,628.7) and decreased activity (OR, 34; 95\% CI, 1.8-633.4), were associated with fatal outcome of sepsis after adjusting for these differences. The appearance of neutropenia in the peripheral blood of newborn infants with sepsis suggests that the neutrophil storage pool is depleted. ${ }^{27)}$ Sepsis in neutropenic patients often presents as severe infections, and it can rapidly progress to 
septic shock and multiple organ dysfunction syndromes and is associated with high mortality. ${ }^{28,29}$ In addition, decreased activity in babies with sepsis can be considered as a clinical symptom related to acute changes in mental status, suggesting severe infection. ${ }^{30}$ Therefore, decreased activity exhibited in the early phase of infection in infants with sepsis, may be associated with a poor prognosis. ${ }^{31}$ This study had some limitations. First, it was retrospective and investigated limited clinical findings that were comparable between the death and survival groups in infants with EOS. Furthermore, it was carried out at a single institution, and the number of subjects was relatively small. However, the results of this study are helpful to understand the clinical features and prognostic factors of EOS. In conclusion, the common pathogens involved in EOS in NICU patients were GBS and E. coli. Moreover, infection caused by gramnegative bacteria, decreased activity in the early phase of infection, and neutropenia are associated with poor outcomes.

\section{Conflicts of interest}

No potential conflict of interest relevant to this article was reported.

\section{References}

1. Stoll BJ, Hansen NI, Sánchez PJ, Faix RG, Poindexter BB, Van Meurs $\mathrm{KP}$, et al. Early onset neonatal sepsis: the burden of group B Streptococcal and E. coli disease continues. Pediatrics 2011;127:817-26.

2. Edwards RK, Jamie WE, Sterner D, Gentry S, Counts K, Duff P. Intrapartum antibiotic prophylaxis and early-onset neonatal sepsis patterns. Infect Dis Obstet Gynecol 2003;11:221-6.

3. Stoll BJ, Hansen N, Fanaroff AA, Wright LL, Carlo WA, Ehrenkranz $\mathrm{RA}$, et al. Changes in pathogens causing early-onset sepsis in verylow-birth-weight infants. N Engl J Med 2002;347:240-7.

4. Lee SM, Chang M, Kim KS. Blood culture proven early onset sepsis and late onset sepsis in very-low-birth-weight infants in Korea. J Korean Med Sci 2015;30 Suppl 1:S67-74.

5. Klinger G, Levy I, Sirota L, Boyko V, Lerner-Geva L, Reichman B; Israel Neonatal Network. Outcome of early-onset sepsis in a national cohort of very low birth weight infants. Pediatrics 2010;125:e736-40.

6. Schuchat A, Zywicki SS, Dinsmoor MJ, Mercer B, Romaguera J, O'Sullivan MJ, et al. Risk factors and opportunities for prevention of early-onset neonatal sepsis: a multicenter case-control study. Pediatrics 2000;105(1 Pt 1):21-6.

7. Kim DH, Lee HJ, Kim HS, Yoo BH. Influence of histologic chorioamnionitis and funisitis on the level of peripheral blood C-reactive protein at birth in preterm infants. Korean J Pediatr 2010;53:33-40.

8. Lee SY, Park KH, Jeong EH, Oh KJ, Ryu A, Park KU. Relationship between maternal serum C-reactive protein, funisitis and early-onset neonatal sepsis. J Korean Med Sci 2012;27:674-80.

9. Simonsen KA, Anderson-Berry AL, Delair SF, Davies HD. Early-onset neonatal sepsis. Clin Microbiol Rev 2014;27:21-47.

10. Fahmey SS. Early-onset sepsis in a neonatal intensive care unit in Beni Suef, Egypt: bacterial isolates and antibiotic resistance pattern. Korean J Pediatr 2013;56:332-7.
11. Shane AL, Stoll BJ. Neonatal sepsis: progress towards improved outcomes. J Infect 2014;68 Suppl 1:S24-32.

12. Verani JR, McGee L, Schrag SJ; Division of Bacterial Diseases, National Center for Immunization and Respiratory Diseases, Centers for Disease Control and Prevention (CDC). Prevention of perinatal group B streptococcal disease--revised guidelines from CDC, 2010. MMWR Recomm Rep 2010;59(RR-10):1-36.

13. Schrag SJ, Farley MM, Petit S, Reingold A, Weston EJ, Pondo T, et al. Epidemiology of invasive early-onset neonatal sepsis, 2005 to 2014. Pediatrics 2016;138:e20162013.

14. Wright AJ, Unger S, Coleman BL, Lam PP, McGeer AJ. Maternal antibiotic exposure and risk of antibiotic resistance in neonatal earlyonset sepsis: a case-cohort study. Pediatr Infect Dis J 2012;31:1206-8.

15. Piening BC, Geffers C, Gastmeier P, Schwab F. Pathogen-specific mortality in very low birth weight infants with primary bloodstream infection. PLoS One 2017;12:e0180134.

16. Kermorvant-Duchemin E, Laborie S, Rabilloud M, Lapillonne A, Claris 0 . Outcome and prognostic factors in neonates with septic shock. Pediatr Crit Care Med 2008;9:186-91.

17. Koo YJ, Lee DH. Hypertension in pregnancy. J Korean Med Assoc 2016;59:24-30.

18. Sale SM. Neonatal apnoea. Best Pract Res Clin Anaesthesiol 2010; 24:323-36.

19. Park HK. Optimal blood pressure in preterm infants. Neonatal Med 2014;21:99-105.

20. Nittala S, Subbarao GC, Maheshwari A. Evaluation of neutropenia and neutrophilia in preterm infants. J Matern Fetal Neonatal Med 2012;25(Suppl 5):100-3.

21. Subramanian S, Agarwal R, Deorari AK, Paul VK, Bagga A. Acute renal failure in neonates. Indian J Pediatr 2008;75:385-91.

22. Karlowicz MG, Buescher ES, Surka AE. Fulminant late-onset sepsis in a neonatal intensive care unit, 1988-1997, and the impact of avoiding empiric vancomycin therapy. Pediatrics 2000;106:1387-90.

23. Stoll BJ, Hansen N, Fanaroff AA, Wright LL, Carlo WA, Ehrenkranz RA, et al. Late-onset sepsis in very low birth weight neonates: the experience of the NICHD Neonatal Research Network. Pediatrics 2002;110(2 Pt 1):285-91.

24. Polin RA; Committee on Fetus and Newborn. Management of neonates with suspected or proven early-onset bacterial sepsis. Pediatrics 2012;129:1006-15.

25. May M, Daley AJ, Donath S, Isaacs D; Australasian Study Group for Neonatal Infections. Early onset neonatal meningitis in Australia and New Zealand, 1992-2002. Arch Dis Child Fetal Neonatal Ed 2005;90: F324-7.

26. Sgro M, Shah PS, Campbell D, Tenuta A, Shivananda S, Lee SK; Canadian Neonatal Network. Early-onset neonatal sepsis: rate and organism pattern between 2003 and 2008. J Perinatol 2011;31:794-8.

27. Engle WA, McGuire WA, Schreiner RL, Yu PL. Neutrophil storage pool depletion in neonates with sepsis and neutropenia. J Pediatr 1988;113:747-9.

28. Tolsma V, Schwebel C, Azoulay E, Darmon M, Souweine B, Vesin A, et al. Sepsis severe or septic shock: outcome according to immune status and immunodeficiency profile. Chest 2014;146:1205-13.

29. Patel A, Gruber P. Severe infections in neutropenic patients. Curr Opin Crit Care 2015;21:586-92.

30. Goldstein B, Giroir B, Randolph A; International Consensus Conference on Pediatric Sepsis. International pediatric sepsis consensus conference: definitions for sepsis and organ dysfunction in pediatrics. Pediatr Crit Care Med 2005;6:2-8.

31. Wynn JL, Wong HR. Pathophysiology and treatment of septic shock in neonates. Clin Perinatol 2010;37:439-79. 